\title{
Production of CD4+ and CD8+ T Cell Hybridomas
}

\section{David H. Canaday}

\section{Abstract}

T cell hybridomas are very useful tools to investigate antigen presenting cell (APC) function. They were developed based on the fusion technology that led to monoclonal antibody section. Antigenspecific primary $\mathrm{T}$ cells are generated and fused to an immortal thymoma line. Unfused thymoma cells are eliminated by engineered metabolic selection. Antigen-specific hybridomas are identified and may be characterized in detail. Primary T cells are preferable for studies of the regulatory mechanisms intrinsic to $\mathrm{T}$ cells, but for study of antigen presentation $\mathrm{T}$ cell hybridomas have advantages over primary $\mathrm{T}$ cell clones, including their relative uniformity, stability over time, and ready availability in large numbers for extensive antigen presentation experiments.

\section{Keywords}

Antigen presentation; T cell hybridoma; Antigen processing; Macrophage; Dendritic cell

\section{Introduction}

Fusion of primary B cells with an immortal fusion partner was developed initially to generate B-cell hybridomas that lead to the development of monoclonal antibody technology (1). A similar process was applied to $\mathrm{T}$ cells to produce $\mathrm{T}$ cell hybridomas that become activated after T cell receptor (TCR) signaling and have some measurable function most commonly IL-2 production $(2,3)$. Since very few antibodies exist that recognize specific major histocompatability (MHC)-peptide complexes on APC, determining levels of antigen presentation by APC necessarily must be done with a bioassay involving T cells (4). T cell hybridomas provide a quantitative measurement of specific MHC-peptide complexes on APC. Most hybridomas are relatively costimulation (CD80 and CD86) independent making them a tool to study pure antigen processing and presentation less affected by costimulatory signals that influence primary $\mathrm{T}$ cells.

$\mathrm{T}$ cell hybridomas have a number of advantages over the primary $\mathrm{T}$ cell lines that they were generated from. Most importantly, their specificity can be very carefully defined. The result is a highly specific, reliable, reproducible, and convenient $\mathrm{T}$ cell reagent that can be grown to large numbers for extensive antigen presentation studies. In contrast to primary $\mathrm{T}$ cells, $\mathrm{T}$ cell hybridomas function well recognizing antigen presented by fixed APC. Fixation creates essentially a total separation of antigen uptake, processing, and presentation pre-fixation and the post-fixation readout of antigen presentation by T cell hybridoma. Fixation of APC allows detailed kinetic studies, use of inhibitors of antigen processing that will not come in 
contact with the $\mathrm{T}$ cell hybridoma readout, and the ability to study antigen presentation of live pathogens such as bacteria and virus that will be sterilized with fixation. T cell hybridomas are not appropriate to study aspects of $\mathrm{T}$ cell differentiation or regulation. Also, they are not suitable for in vivo experiments because they produce tumors in mice.

The process of making $\mathrm{T}$ cell hybridomas involves generating an activated antigen-specific $\mathrm{T}$ cell line that is fused to a fusion partner that can immortalize the primary $\mathrm{T}$ cell. A number of technical advances over the years have been applied to ease production of $\mathrm{T}$ cell hybridoma clones and maximize success in generating an antigen-specific hybridoma. The widely used version of fusion partner (BW5147) is a T thymoma line, which cannot survive in hypoxanthine/aminopterin/thymidine (HAT) selection medium unless it has successfully fused with a primary $\mathrm{T}$ cell. Additionally optimized fusion partners do not express endogenous TCR so there is no chance for the fusion partner's TCR $\alpha$ and $\beta$ chains to combine with the primary T cell's TCR (5). The most effective fusion partner to generate CD8+ T cell hybridomas has been transfected with the CD8 molecule to maintain high CD8 levels even after fusion $(3,6,7)$.

\section{Materials}

1. Mice of appropriate MHC type for in vivo priming with desired antigen (see Note $1)$.

2. Adjuvant for in vivo immunization and priming. Complete Freund's adjuvant (CFA) or incomplete Freund's adjuvant (IFA) are used most commonly.

3. Antigen or peptide for immunization and in vitro stimulation (see Note 2).

4. Glass syringes and Popper micro-emulsifying needle with reinforcement or a 3-way stopcock to create emulsion.

5. 50\% (w/v) Polyethylene glycol (PEG): PEG 1500 in 75 mM HEPES 50\% (w/v) from Roche is recommended.

6. 6/24/96-Well plates.

7. T25 Flasks.

8. $1 \times$ PBS sterile.

9. Dissecting instruments (scissors and forceps).

10. Culture dishes.

\footnotetext{
${ }^{1}$ Standard commercially available mouse strains such as C57BL/6 or BALB are used most commonly to generate T cells that recognize antigens presented by murine APC. For human studies we and others have used HLA-transgenic mice to generate HLArestricted T cell hybridomas that readily recognize human APC. The key to this is obtaining the HLA-transgenic mice. Several HLAA and HLA-B expressing transgenic mice are available from Taconic and Jackson Laboratories. An HLA-DR4 transgenic mouse is available from Taconic. Transgenic mice expressing HLA-DR1, DR15, and DR3 have also been generated by other laboratories (8$10)$. We have used these mice to generate murine T cell hybridomas that respond readily to a range of human APC from monocytes, B cells, and dendritic cells (11-13). The methods to generate these HLA-restricted T cell hybridomas are identical to those described above with only one significant change. We use human APC for the screening after the fusion. This is important because hybridomas not capable of recognizing human APC presented antigen or that have a significant allogenic response are not useful. We use HLAmatched EBV-transformed B cells as the screening APC.

${ }^{2}$ Plan on 5-25 $\mu \mathrm{g}$ per animal for the immunization depending on the robustness of the antigen and immune response expected. Some antigen/adjuvant is lost in preparation of the emulsion so extra must be made.
} 
11. $1 \mathrm{ml}$ Syringe.

12. DMEM unsupplemented.

13. Culture medium: DMEM, $10 \%$ fetal calf serum (FCS), $5 \times 10^{-5} \mathrm{M} 2$-mercaptoethanol, $1 \%$ nonessential amino acids, $10 \mathrm{mM}$ HEPES, $100 \mathrm{U} / \mathrm{ml}$ Penicillin/ Streptomycin, $10 \mathrm{mg} / \mathrm{ml}$ Ciprofloxacin (see Note 3).

14. Murine or human IL-2. Both work well.

15. HAT and hypoxanthine/thymidine (HT) (see Note 4).

16. BW5147 fusion partner called BW5147.G.1.4 (ATCC, TIB-48). Other derivative lines such as BW1100 or BW5147-CD8 transfected can also be used but are not commercially available (see Notes 5 and ${ }^{6}$ ).

17. APC in the same MHC restriction as the mouse at immunization. Primary splenocytes or bone marrow-derived macrophages (BMM) used most commonly.

18. Murine IL-2 detection system, either ELISA or CTLL-2 Bioassay (see Note 7).

19. Freeze medium: $90 \%$ FCS, $10 \%$ DMSO.

20. Freezing container (Nalgene Mr. Frosty) or vermiculite containing box.

21. Water bath that can fit in the hood or flask with water at $37^{\circ} \mathrm{C}$.

\section{Methods}

\subsection{Generate Antigen-Specific T Cells}

1. Adjuvant antigen mixture preparation. For peptides use 5-20 $\mu \mathrm{g} /$ mouse in IFA. For soluble antigen use $10-25 \mathrm{mg} /$ mouse in CFA. We use a 16 or $20 \mathrm{G}$ Popper microemulsifying needle with reinforcement with glass syringes on each side to prepare the adjuvant. Make a 50/50 mixture of CFA or IFA and antigen or peptide in PBS. Plan on immunizing each mouse $50 \mu \mathrm{l}$ of the adjuvant/antigen mixture. Draw up equal volumes of CFA or IFA in one syringe and antigen in PBS in the other.

\footnotetext{
${ }^{3}$ Ciprofloxacin is added to minimize mycoplasma contamination that can be a significant risk factor in the HAT and HT selection process.

${ }^{4}$ We use fresh HAT every time as it is not that expensive and it comes in single vials (Sigma) that are resuspended at time of use. The HAT is very important to successful generation of hybridomas because the unfused fusion partner must die before the harvest process begins at days $7-10$.

${ }^{5}$ Although we suggest the ATCC BW-5147 basic line, it is not the optimal line to use for hybridoma generation. It does not have all of the TCR genes deleted so it is possible to have some recombinations that do not produce antigen-specific $\mathrm{T}$ cells. We use a derivative of BW5147 that has the TCR genes eliminated called BW1100. If this is not available or cannot be obtained collaboratively, the basic ATCC BW-5147 generally works reasonably well however.

${ }^{6}$ For MHC-I hybridomas it has been shown that having a CD8-transfected BW5147 line increases the frequency of MHC-I-restricted lines generated (3). At least three groups have developed CD8-transfected BW5147 to optimally generate CD8 expressing T cell hybridomas $(3,6,7)$. The standard BW5147 does not support continued expression of CD8 after fusion.

${ }^{7}$ For the IL-2 measurement there are several techniques possible. We prefer CTLL-2 cells during the development of the hybridomas. We use a colorimetric readout rather than $\mathrm{H}^{3}$ thymidine for this assay as well $(11,14,15)$. CTLL-2 cells can be obtained from ATCC (TIB-214). Some care and time have to be used to keep them successfully in passage as they are an IL-2-dependent cell line. The advantage is that they are inexpensive to use and require a few short bits of time to spin and add them to your supernatants rather than more expensive and time intensive ELISA assays. The amount of IL-2 generated from hybridomas is fairly significant in the 300$4,000 \mathrm{pg} / \mathrm{ml}$ range so a highly sensitive IL-2 ELISA is not necessary. For that reason we use a "homebrew" IL-2 ELISA using the recommended IL-2 antibody pair from EBiosciences. Many suppliers sell such antibody pairs. Standard commercial IL-2 ELISA kits are also widely available.
} 
Screw each syringe onto the metal tube and inject it back and forth for 2-20 min to generate a firm emulsion (see Note 8 ).

2. Immunize mice in an area with a clear lymphatic drainage. Footpad or base of tail are the most common sites. Immunize with about $50 \mu \mathrm{l}$ of adjuvant/antigen per site (see Note 9).

3. At day 7, harvest the draining lymph nodes. For footpad harvest the popliteal lymph nodes. For base of tail injection harvest the inguinal lymph nodes.

4. Add the lymph nodes to 3-4 $\mathrm{ml}$ of DMEM in a small tissue culture dish. The lymph nodes are crushed against the bottom of the dish to free the cells. We use the back flat part of a disposable sterile $1 \mathrm{ml}$ syringe that is normally where the thumb presses down to inject. Make sure each chunk of lymph node gets crushed against the bottom of the dish two or three times.

5. Harvest the cell containing supernatant and leave any tissue chunks behind.

6. Spin the cells at $200 \times g$ for $10 \mathrm{~min}$ and resuspend them in complete medium.

7. Culture the cells in $24-w e l l$ plates at 5-8 million cells per well with $1-10 \mu \mathrm{g} / \mathrm{ml}$ of antigen or peptide (see Notes 10 and ${ }^{11}$ ).

8. On the day of harvest of the lymph nodes, thaw the fusion partner and begin to expand this up so it is ready for fusion in 5 days. If you will have a massive amount lymph node cells ( $>10^{7}$ cells from immunization of over four mice) then thaw the cells prior to the lymph node harvest day to grow them to sufficient quantity.

9. At day 4 , add $10-20 \mathrm{U} / \mathrm{ml}$ of $\mathrm{IL}-2$ to each restimulation well.

10. At day 5 , harvest the cells, spin them at $200 \times g$ for $10 \mathrm{~min}$, and resuspend them in DMEM for counting.

\subsection{Fusion (Day 5)}

1. On the day of the fusion, warm $1 \mathrm{ml}$ of PEG, $20 \mathrm{ml}$ of DMEM, and $30 \mathrm{ml}$ of complete medium at $37^{\circ} \mathrm{C}$. Take several serologic pipettes ( 1 and $5 \mathrm{ml}$ sizes) and

\footnotetext{
${ }^{8} \mathrm{Be}$ careful to make sure the syringe is tight onto the metal lock. If a stiff emulsion is very slow to develop then put the syringes at $4^{\circ} \mathrm{C}$ for $20-60 \mathrm{~min}$ and continue mixing. This cooling step can facilitate development of a proper emulsion. When the emulsion is ready, it will be much harder to push through the metal tube. This condition often develops quite suddenly. Plastic syringes should be avoided as the black rubber breaks down and turns the emulsion gray, and also they are prone to leak. To test the emulsion, squeeze a tiny amount onto water in a Petri dish. There should be minimal or no oil leakage from the white emulsion. If there is a lot of oil leakage then keep squirting back and forth until it solidifies.

${ }^{9}$ We use the popliteal lymph node as our preferred site of immunization. This means immunization generally with CFA into the footpad. We do not boost after this type of immunization. We have never seen a foot ulcer after hundreds of immunizations over the years. If your IACUC is concerned over footpad injections with CFA, a few options can be considered. A commonly used option is base of the tail immunization. Another possible site if you still want to harvest popliteal lymph node is to employ hock (lower leg below the knee) immunization. This has been shown to be the same as footpad injection (16).

${ }^{10}$ It is important to have an activated antigen-specific cell line for fusion. The key reason for failure to generate antigen-specific hybridomas once you master the physical techniques is fusion with a poor primary $\mathrm{T}$ cell line. For very low precursor frequency $\mathrm{T}$ cells it may be necessary to immunize and boost in vivo. Another option we have used for MHC-I restricted lines is to do two rounds of in vitro restimulation. If this is planned, an enormous amount of cell death after the second round of restimulation should be expected. In spite of this, we have had success with fusion of less than a million cells in the past.

${ }^{11}$ It is possible to screen the lines before fusion if there is concern that there will be very few antigen-specific cells. We have used intracytoplasmic staining most often in the past to perform this task (11). If we had on the order of $0.5-1 \%$ antigen-specific cells, generally this still lead to a successful fusion.
} 
put them in the incubator. Have a small water bath at $37^{\circ} \mathrm{C}$ or an Erlenmeyer flask of water at $37^{\circ} \mathrm{C}$ that can fit inside of the hood. After all of these components are at $37^{\circ} \mathrm{C}$ begin to prepare the fusion partner.

2. Spin down and count the fusion partner that was being expanded for at least the last 5 days.

3. Add lymph node cells from above and fusion partner in a $1: 1$ ratio to a $50 \mathrm{ml}$ conical tube and spin the cells.

4. Aspirate the supernatant carefully to have the pellet be as dry as possible without aspirating the cells.

5. Prepare a timer to count 2,5 , and 2 min.

6. Add $0.4 \mathrm{ml}$ of warm PEG to the cell pellet very slowly drop wise over $2 \mathrm{~min}$. Have the bottom of the tube in the warm water bath or flask so that the whole fusion takes place at $37^{\circ} \mathrm{C}$. Gently mix the cells by stirring stir between drops with the PEG containing pipette.

7. Bring up $2 \mathrm{ml}$ of warm DMEM in a warm pipette and add it very slowly drop wise to the suspension over 5 min with stirring between drops.

8. Next draw up $5 \mathrm{ml}$ of DMEM and add it drop wise over $2 \mathrm{~min}$ while stirring.

9. Spin the cells gently at $200 \times g$ for $10 \mathrm{~min}$.

10. After aspiration of supernatant, draw up $10 \mathrm{ml}$ of complete medium in a pipette and tap the tube at the tip while adding $1-2 \mathrm{ml}$ at a time of medium initially to loosen the pellet and then resuspend it. If there are still chunks of cells present after adding the first $10 \mathrm{ml}$ then slowly pipette up and down once to help resuspend the cells. Finish by adding $20 \mathrm{ml}$ more of complete medium.

11. Put the cells in a $37^{\circ} \mathrm{C}$ water bath to recover.

12. After $1 \mathrm{~h}$ perform serial fivefold dilution of the cells by taking $6 \mathrm{ml}$ of the preceding dilution into $24 \mathrm{ml}$ of complete medium to create the 1:5, 1:25, and $1: 125$ dilutions.

13. Label 8 round bottom 96-well plates with two plates for each dilution (neat, 1:5, $1: 25$, and 1:125).

14. Pipette $100 \mu \mathrm{l}$ per well to fill the plates for each dilution.

15. The next day add $100 \mu \mathrm{l}$ of $2 \times$ HAT solution in complete medium to every well.

\subsection{Harvest the T Cell Hybridomas}

1. Starting at day 7 begin to check the hybridoma plates. Hold the 96 -well plates above your head to observe the pellet size. The cells were plated in round wells to allow a very quick visual screening to determine which wells are ready for harvesting and which wells need more time or have no growth. Wells that have a pellet size of $2-3 \mathrm{~mm}$ or that the medium is beginning to change color should be marked on the bottom of the well with a dark marker (see Notes 12 and ${ }^{13}$ ). 
2. Pipette up and down the marked wells and transfer them into 24-well plates. Most importantly mark on the plate lid what dilution the hybridomas came from.

3. Add $1 \mathrm{ml}$ per well of $1 \times \mathrm{HT}$ in complete medium to the 24 -well plates.

4. Continue to harvest the 96 -well plates daily for the next 2 days.

\subsection{Screening}

1. After 2 or 3 days the 24 -well plates are ready for screening. The wells will be 30 $80 \%$ confluent which is often at or near the time when the medium begins to change color.

2. Prepare APC for the screening. Splenocytes $\left(2 \times 10^{5} /\right.$ well $)$ can be used fresh or cultured in complete medium in 96-well plates for 1-2 days in advance to have them ready for the successive days of screening. If BMM $\left(5 \times 10^{5} /\right.$ well $)$ are used, they need to be treated with IFN-gamma at least 1 day prior to screening to upregulate MHC-II levels. Irradiation is not needed for any APC in this 1-day assay.

3. Open both your plates with APC and hybridomas place them side by side. Pipette up and down twice with a $1 \mathrm{ml}$ pipette one row at a time from the 24-well plate. Use a new tip with every well to not cross-contaminate hybridomas.

4. Add $100 \mu \mathrm{l}$ of hybridomas to up and down rows in your APC plate from the 6 wells that were just resuspended. For example, the first wells are A1 and B1, second A2, B2, etc. The top row will be the no antigen row and the row beneath will be the antigen row. You can therefore screen 2 full 24-well hybridomas containing plates with a single 96-well plate of APC.

5. Add complete medium to the top row and antigen to the second row to have $200 \mu \mathrm{l}$ volume in all wells for the overnight antigen presentation assay.

6. Take the 24-well plates with the hybridomas in them and aspirate the cells and media to near empty then re fill them with HT containing medium to keep them alive while you await the screening results to determine which wells have promising hybridomas in them.

7. After $20-24 \mathrm{~h}$ harvest $100 \mu \mathrm{l}$ of supernatant from each screening plate to $96-$ well plates.

8. Assay for IL-2 production as soon as possible. If IL-2 ELISAs will be performed, do them that day or the next. If CTLL-2 are used then start this right away. The urgency is that you have to keep the hybridomas in the 24-well plates alive while you await the screening results. The 24-well plates have to be examined daily and media and cells aspirated and refed with HT containing complete medium to keep

\footnotetext{
${ }^{12}$ The investigator has to decide how many wells they plan to harvest for screening. Ideally hybridomas from plates that have 10 wells or less that grow on that dilution are more likely to be clonal. If it is uncertain how good of an immunization and $\mathrm{T}$ cell line were generated, it is better to err on the side of screening more wells. In a typical fusion we will harvest 100-200 wells total over 3 days for screening.

${ }^{13}$ The harvesting and screenings of the T cell hybridomas requires nearly 2 weeks of daily work.
} 
them from getting to dense. T cell hydridomas apoptose fairly readily when they overgrow. One day of overgrowth may kill the lines (see Note 14).

9. The screening is not an exact process as precise numbers of hybridomas per well were not determined and it was only a singlet assay. All wells with IL-2 signal over background are then expanded up to 6-well plates or T25 flasks for a secondary screening to con firm antigen specifically and determine the sensitivity of the lines.

\subsection{Secondary Screening}

1. Monitor harvested hybridomas in 6-well plates or T25 flasks until they are 50-80\% confluent then spin them down and count.

2. Perform antigen presentation assays as described above except set up the wells in duplicate or triplicate $\left(1 \times 10^{5}\right.$ hybridoma/well $)$ and use a series of concentrations of antigen to determine which lines are most sensitive.

3. If the most sensitive lines came from 96-well plates that had over 10 wells that grew then perform subcloning.

4. Freeze down several vials of the most promising lines at the time of subcloning to have backup (see Subheading 3.7).

\subsection{Subcloning}

1. Spin down cells and count. Dilute the cells and make two plates of $1,0.3$, and 0.1 hybridoma/well in round bottom 96-well plates.

2. Monitor the plates as growth takes 5-10 days at this point. Select subclones from plates that have ten hybridomas growing or less. Expand them up in T25 flasks when the pellet button is in the $2-3 \mathrm{~mm}$ range.

3. Screen the clones as above and cryopreserve the antigen-specific subclones (see Note 15).

\subsection{Cryopreservation of T Hybridomas}

1. Spin the cells and resuspend in $1 \mathrm{ml}$ freeze medium per vial to have 1-10 million cells per vial (see Note 16).

2. Place in Cryo-baby or box of vermiculite.

3. Transfer to liquid nitrogen within 2 weeks.

\footnotetext{
${ }^{14}$ It is important not to allow the $\mathrm{T}$ cell hybridomas to overgrow as they apoptose and will visually develop a lot of vacuolization and blebbing. Sometimes they can be passed and salvaged, but often lines are lost if they grow too thick.

${ }^{15}$ The vast majority of $\mathrm{T}$ cell hybridoma clones we have generated are able to maintain their antigen specificity and sensitivity for several months in continuous culture.

${ }^{16}$ If experiments with T cell hybridomas are planned intermittently, then large vials of 8-15 million cells per vial can be cryopreserved. The hybridoma vials can be thawed at the time of use and added in the typical $1 \times 10^{5}$ cells per well for antigen presentation assays. In preliminary work for several published manuscripts, we determined that the sensitivity of the freshly thawed hybridomas compared to hybridomas in continuous culture was similar $(12,17)$.
} 


\section{Acknowledgment}

This work was supported by CSR\&D VA Merit grant and NIH grant AI080313.

\section{References}

1. Kohler G, Milstein C. Continuous cultures of fused cells secreting antibody of predefined specificity. Nature. 1975; 256(5517):495-497. [PubMed: 1172191]

2. Kappler JW, Skidmore B, White J, Marrack P. Antigen-inducible, H-2-restricted, interleukin-2producing T cell hybridomas. Lack of independent antigen and H-2 recognition. J Exp Med. 1981; 153(5):1198-1214. [PubMed: 6166712]

3. Rock KL, Rothstein L, Gamble S. Generation of class I MHC-restricted T-T hybridomas. J Immunol. 1990; 145(3):804-811. [PubMed: 2115542]

4. Zhong G, Reis e Sousa C, Germain RN. Production, specificity, and functionality of monoclonal antibodies to specific peptidemajor histocompatibility complex class II complexes formed by processing of exogenous protein. Proc Natl Acad Sci USA. 1997; 94(25):13856-13861. [PubMed: 9391117]

5. Born W, White J, O'Brien R, Kubo R. Development of T cell receptor expression: studies using T cell hybridomas. Immunol Res. 1988; 7(4):279-291. [PubMed: 3066827]

6. Burgert HG, White J, Weltzien HU, Marrack P, Kappler JW. Reactivity of V beta 17a + CD8+ T cell hybrids. Analysis using a new CD8+ T cell fusion partner. J Exp Med. 1989; 170(6):18871904. [PubMed: 2511267]

7. Kanagawa O, Maki R. Inhibition of MHC class II-restricted T cell response by Lyt-2 alloantigen. J Exp Med. 1989; 170(3):901-912. [PubMed: 2475576]

8. Rosloniec EF, Brand DD, Myers LK, Whittington KB, Gumanovskaya M, Zaller DM, Woods A, Altmann DM, Stuart JM, Kang AH. An HLA-DR1 transgene confers susceptibility to collageninduced arthritis elicited with human type II collagen. J Exp Med. 1997; 185(6):1113-1122. [PubMed: 9091584]

9. Kong YC, Lomo LC, Motte RW, Giraldo AA, Baisch J, Strauss G, Hammerling GJ, David CS. HLA-DRB 1 polymorphism determines susceptibility to autoimmune thyroiditis in transgenic mice: definitive association with HLA-DRB1*0301 (DR3) gene. J Exp Med. 1996; 184(3):1167-1172. [PubMed: 9064334]

10. Finn TP, Jones RE, Rich C, Dahan R, Link J, David CS, Chou YK, Offner H, Vandenbark AA. HLA-DRB $1 * 1501$ risk association in multiple sclerosis may not be related to presentation of myelin epitopes. J Neurosci Res. 2004; 78(1):100-114. [PubMed: 15372502]

11. Canaday DH, Gehring A, Leonard EG, Eilertson B, Schreiber JR, Harding CV, Boom WH. T-cell hybridomas from HLA-transgenic mice as tools for analysis of human antigen processing. $\mathrm{J}$ Immunol Methods. 2003; 281(1-2):129-142. [PubMed: 14580887]

12. Woc-Colburn L, Smultea L, Ramachandra L, Canaday DH. Preserved MHC class II antigen processing in monocytes from HIV-infected individuals. PLoS One. 2010; 5(3):e9491. [PubMed: 20209134]

13. Jones L, McDonald D, Canaday DH. Rapid MHC-II antigen presentation of HIV type 1 by human dendritic cells. AIDS Res Hum Retroviruses. 2007; 23(6):812-816. [PubMed: 17604545]

14. Ahmed SA, Gogal RM Jr, Walsh JE. A new rapid and simple non-radioactive assay to monitor and determine the proliferation of lymphocytes: an alternative to $[3 \mathrm{H}]$ thymidine incorporation assay. $\mathrm{J}$ Immunol Methods. 1994; 170(2):211-224. [PubMed: 8157999]

15. Kwack K, Lynch RG. A new non-radioactive method for IL-2 bioassay. Mol Cells. 2000; 10(5): 575-578. [PubMed: 11101150]

16. Kamala T. Hock immunization: a humane alternative to mouse footpad injections. J Immunol Methods. 2007; 328(1-2):204-214. doi:S0022-1759(07)00248-7 [pii] 10.1016/j.jim.2007.08.004. [PubMed: 17804011]

17. Canaday DH, Burant CJ, Jones L, Aung H, Woc-Colburn L, Anthony DD. Preserved MHC-II antigen processing and presentation function in chronic HCV infection. Cell Immunol. 2011; 
266(2):187-191. doi:S0008-8749(10)00259-5 [pii] 10.1016/j.cellimm.2010.10.003. [PubMed: 21055734] 